This item was submitted to Loughborough's Research Repository by the author.

Items in Figshare are protected by copyright, with all rights reserved, unless otherwise indicated.

\title{
Influence of array interspacing on the force required for successful microneedle skin penetration: theoretical and practical approaches
}

\section{PLEASE CITE THE PUBLISHED VERSION}

http://dx.doi.org/10.1002/jps.23439

\section{PUBLISHER}

(c) Wiley Periodicals, Inc. and the American Pharmacists Association

\section{VERSION}

AM (Accepted Manuscript)

\section{PUBLISHER STATEMENT}

This work is made available according to the conditions of the Creative Commons Attribution-NonCommercialNoDerivatives 4.0 International (CC BY-NC-ND 4.0) licence. Full details of this licence are available at: https://creativecommons.org/licenses/by-nc-nd/4.0/

\section{LICENCE}

CC BY-NC-ND 4.0

\section{REPOSITORY RECORD}

Olatunji, Ololade, Diganta Bhusan Das, Martin J. Garland, Luc Belaid, and Ryan F. Donnelly. 2014. "Influence of Array Interspacing on the Force Required for Successful Microneedle Skin Penetration: Theoretical and Practical Approaches". figshare. https://hdl.handle.net/2134/16539. 
Influence of Array Interspacing on the Force required for Successful Microneedle Skin Penetration: Theoretical and Practical Approaches

Ololade Olatunji ${ }^{1}$, Diganta B. Das ${ }^{1, *}$, Martin J Garland ${ }^{2}$, Luc Belaid ${ }^{2}$, Ryan F Donnelly ${ }^{2}$

1 Department of Chemical Engineering, Loughborough University, Loughborough LE11 3TU, United Kingdom

2 School of Pharmacy, Queen's University Belfast, 97 Lisburn Road, Belfast BT9 7BL, Northern Ireland, United Kingdom

Running title: Effect of interspacing on microneedle insertion force

*Corresponding author

Dr Diganta B. Das, Department of Chemical Engineering, Loughborough University, Loughborough, LE11 3TU, UK

Tel: +44 1509 222509; Fax +44(0)1509 22 3923; Email: D.B.Das@lboro.ac.uk 


\begin{abstract}
Insertion behaviour of microneedle (MN) arrays depends upon the mechanical properties of the skin and, MN geometry and distribution in an array. In addressing this issue, this paper studies MN array insertion mechanism into skin and provides a simple quantitative basis to relate the insertion force with distance between MNs. The presented framework is based on drawing an analogy between a beam on an elastic foundation and mechanism of needle insertion, where insertion force is separated into different components. Theoretical analysis indicates that insertion force decreases as interspacing increases. For a specified skin type, insertion force decreased from $0.029 \mathrm{~N} / \mathrm{MN}$ to $0.028 \mathrm{~N} / \mathrm{MN}$ when interspacing at $\mathrm{MN}$ tip was increased from $50 \mu \mathrm{m}(350 \mu \mathrm{m}$ at $\mathrm{MN}$ base) to $150 \mu \mathrm{m}(450 \mu \mathrm{m}$ at $\mathrm{MN}$ base). However, dependence of insertion force seems to decrease as the interspacing is increased beyond $150 \mu \mathrm{m}$. To assess validity of the proposed model, a series of experiments were carried out to determine the force required for skin insertion of MN. Experiments performed at insertion speed of $0.5 \mathrm{~mm} / \mathrm{s}$ and $1.0 \mathrm{~mm} / \mathrm{s}$ yielded insertion force values of $0.030 \mathrm{~N}$ and $0.0216 \mathrm{~N}$ for $30 \mu \mathrm{m}$ interspacing at $\mathrm{MN}$ base $(330 \mu \mathrm{m}$ interspacing at tip) and $0.028 \mathrm{~N}$ and $0.0214 \mathrm{~N}$ for $600 \mu \mathrm{m}$ interspacing at $\mathrm{MN}$ base $(900 \mu \mathrm{m}$ interspacing at tip). Results from theoretical analysis and finite element modelling agree well with experimental results, which_show MN interspacing only begins to affect insertion force at low interspacing $(<150 \mu \mathrm{m}$ interspacing at MN base). This model provides a framework for optimising MN devices, and should aid development of suitable application method and determination of force for reliable insertion into skin.
\end{abstract}

Keywords: Microneedle, microneedle distribution, microneedle interspacing, skin mechanical property, microfabrication, numerical modelling

\title{
1. Introduction
}

Microneedle arrays are minimally invasive devices that can be used to by-pass the stratum corneum barrier and thus achieve enhanced transdermal drug delivery. Microneedles (MN) (50-900 $\mu \mathrm{m}$ in height, up to 20,000 $\mathrm{MNs} \mathrm{cm}^{-2}$ ) in diverse geometries have been produced from silicon, metal, carbohydrates and polymers using various microfabrication techniques (Henry et al., 1998; Prausnitz, 2004; Crichton et al., 2010). Recently, there has beenincreasing interest in investigating the influence of a variety of variables related to the use of $\mathrm{MN}$, in order to reach an optimum $\mathrm{MN}$ design for transdermal drug delivery 
(Aggarwal et al., 2004; Davis et al., 2004; Verbaan et al., 2008; Olatunji et al., 2012). In particular it has been shown that the height and density of MNs on an array can affect the rate and extent of drug delivery achieved (Verbaan et al., 2008; Oh et al., 2008; Yan et al., 2010) including some of our previous work (Al-Qallaf et al., et al., 2007; Al-Qallaf and Das, 2008; Davidson, et al., 2008; Al-Qallaf and Das, 2009a,b; Al-Qallaf et al., et al., 2009a,b; Olatunji et al., 2012).

In order for the MN technology to become a clinical reality, there are a number of challenges that need to be overcome. MN arrays should be able to demonstrate sufficient strength to penetrate into the skin or other biological tissue without breaking or bending before or during insertion (Aggarwal et al., 2004). The major factors accountable for MN performance are type of material, needle height, tip-radius, base diameter, needle geometry and needle density, which, in turn, determine the overall insertion and fracture force of the MN (Davis et al., 2004). The inherent elasticity and irregular surface of the skin remains a major challenge to the reproducibility of MN penetration. It has been shown that the skin can become folded around $\mathrm{MN}$, which results in either partial or incomplete piercing depending upon MN height (Verbaan et al., 2008). As such, there is a greater need to understand the force required for reproducible skin penetration to be achieved for a given MN design. Recently, it has been shown that the depth of MN penetration into the skin is critically dependent upon the force used for MN application (Donnelly et al., 2010). This finding suggests that to ensure consistent MN penetration on a patient - to - patient basis, it may be necessary to develop a suitable application method and device, rather than relying on manual insertion of MNs. Indeed, the use of applicator devices has been shown to provide superior MN penetration into skin in comparison to manual application (Verbaan et al., 2008).

In order to fully understand the MN insertion process, and how this is influenced by the density of $\mathrm{MN}$ on an array, it is necessary to develop a model that identifies each of the forces and stages that are involved in the penetration of MN into skin. Soft tissue such as skin, in reality, is an inhomogeneous material that exhibits non-linear anisotropic, elastic and viscous behaviour. These properties make the modelling of skin deformation rather complex. This is an area of research that has attracted a considerable amount of attention in recent years (Okamura et al., 2004; Simone and Okamura, 2002, Simone, 2002, DiMaio and Salcudeen, 2002; DiMaio and Salcudeen, 2005; DiMaio, 2005), with accurate modelling of needle insertion useful for medical purposes such as training through realistic surgical 
simulation and planning prior to surgery and monitoring of robot assisted surgeries (Yan et al., 2009).

A novel approach to modelling and simulation of needle insertion into soft tissue was presented by DiMaio and Salcudean (2003). The authors inserted a needle into marked and calibrated artificial tissue. Using computer visualization, they measured the needle and tissue deformation on insertion. The force distribution along the needle shaft was then estimated through computer aided visual observation. This was then followed up by their work to present a novel interactive virtual needle insertion simulation. The deformation of both the tissue and needle was modelled in 3D and solved using fast numerical techniques which they developed (DiMaio and Salcudean, 2003). The findings from this study highlighted a relationship between force applied to the needle and tissue deformation and presents a method to analyse tissue deformation based on needle forces.

In other studies (Marvarsh and Hayward, 2001; Maurin et al., 2004), needle insertion was separated into 3 phases based on results obtained from experiments performed on bovine liver tissue. These forces include deformation (without penetration), steady state penetration, relaxation and extraction. Azar and Hayward (2008) related crack size, needle diameter and tip geometry to insertion force. The process of insertion was accounted for as an interchange of energy between work done by the needle, work of fracture of tissue, work against friction and change in recoverable strain energy. In a separate study, Yan et al.(2009) proposed a spring beam damper model to describe needle-tissue interaction during insertion. The work was aimed towards developing physically based needle steering systems to achieve more accurate needle placement during medical procedures such as biopsies and treatment injections, by taking into consideration the needle deflection during insertion and the inhomogeneity of tissue. The developed model creates an online parameter estimation that allows the depth varying parameter to be controlled, thereby preventing inaccurate targeting.

All the studies discussed above focus on modelling the insertion of a single needle into soft tissue. However, in reality most MN devices consist of an array of regularly spaced MNs that are inserted into skin. For optimum drug delivery, and clinician/patient acceptability, it is important that the MNs are capable of inserting into skin, reliably and reproducibly. On this basis, this study aims to provide a fundamental framework that relates the distribution of MNs within an array, in terms of MN interspacing, with the insertion mechanism of a MN 
array into skin. In doing so, this study proposes mathematical models to relate $\mathrm{MN}$ interspacing to $\mathrm{MN}$ insertion force by isolating the forces that exists in the different phases of insertion, using constitutive equations. Furthermore, to assess the validity of the proposed model a series of in vitro experiments were conducted to determine the force required for $\mathrm{MN}$ insertion into neonatal porcine skin, over a range of MN interspacing. This model may be useful for the early stages of MN device development, enabling a prediction of the optimum array density for a given MN design such that the potential for enhanced drug delivery is not compromised by the ability of the MN to penetrate into skin.

\section{Materials and Methods}

\subsection{Materials}

Gantrez ${ }^{\circledR}$ AN-139, a copolymer of methylvinylether and maleic anhydride (PMVE/MA) was provided by ISP Co. Ltd, Guildford, UK). Methylene blue was obtained from Sigma Aldrich, Dorset, UK. Silicone elastomer LSR9-9508-30 was obtained from Polymer Systems Technology, Wycombe, UK. Silastic ${ }^{\circledR}$ 9280/60E silicone elastomer was obtained from Dow Corning, Wiesbaden, Germany.

\subsection{Fabrication of microneedles}

A $20 \%$ w/w aqueous solution of PMVE/MA was prepared by adding the required mass of $\mathrm{PMVE} / \mathrm{MA}$ to ice cold deionised water, followed by vigorous stirring and heating at $95.0^{\circ} \mathrm{C}$ until a clear gel was obtained, due to hydrolysis of the anhydride form of the copolymer to the corresponding acid. Upon cooling, the blend was then readjusted to the final concentration of $20 \% \mathrm{w} / \mathrm{w}$ by addition of an appropriate amount of deionised water. $\mathrm{MN}$ arrays were prepared from aqueous blends of 20\% w/w PMVE/MA using laser engineered silicone micromould templates, as described previously (Donnelly et al., 2011). Briefly, silicone elastomer (Silastic ${ }^{\circledR}$ 9280/60E, obtained from Dow Corning, Wiesbaden, Germany) was poured into a custom-made aluminium mould and cured overnight at $40^{\circ} \mathrm{C}$. A lasermachine tool (BluLase ${ }^{\circledR}$ Micromachning System, Blueacre Technology, Dundalk, Ireland) with a laser (Coherent Avia, Coherent Inc., Pittsburgh, USA) emitting a beam having a wavelength of $355 \mathrm{~nm}$ and a pulse length of $30 \mathrm{~ns}$ (variable from $1-100 \mathrm{kHz}$ ), was then employed to produce MN moulds with a definable height, width and interspacing (Figure 1). The 20\% w/w PMVE/MA solution was poured into laser engineered silicone micromould 
templates, centrifuged for 15.0 minutes at $3500 \mathrm{rpm}$ and allowed to dry under ambient conditions for 24 hours. A total of $5 \mathrm{MN}$ geometries were prepared for subsequent characterisation (Table 1).

\subsection{Measurement of MN insertion force into excised neonatal porcine skin.}

The force required to insert PMVE/MA MN array at two different insertion speeds, $0.5 \mathrm{~mm} \mathrm{~s}^{-}$

${ }^{1}$ and $1.0 \mathrm{~mm} \mathrm{~s}^{-1}$, into excised neonatal porcine skin was determined using a TA.XT-plus Texture Analyser (Stable Micro Systems, Surrey, UK), as described previously (Donnelly et al., 2011). Neonatal porcine skin, a good model for human skin in terms of hair sparseness and physical properties (Woolfson et al., 1995; Fourtanier and Berrebi, 1989), was obtained from stillborn piglets and immediately ( $<24 \mathrm{~h}$ after birth) excised and trimmed to a thickness of $700 \mu \mathrm{m}$ using an electric dermatome (Integra Life Sciences ${ }^{\mathrm{TM}}$, Padgett Instruments, NJ, USA). Skin was then stored in aluminium foil at $-20^{\circ} \mathrm{C}$ until further use. Using double sided adhesive tape, MN arrays were carefully attached to the moveable cylindrical probe. The stratum corneum surface of the skin was dried with tissue paper, and the skin was placed, dermis side down, on a $500 \mu$ m thick sheet of dental wax, and this assembly was then secured on a wooden block for support. The probe was lowered onto the skin at a speed of either 0.5 $\mathrm{mm} \mathrm{s}^{-1}$ or $1.0 \mathrm{~mm} \mathrm{~s}^{-1}$ until the desired force was exerted. Forces were held for $30 \mathrm{~s}$ and were increased gradually from a force of $0.0056 \mathrm{~N}$ per $\mathrm{MN}$ (obtained by dividing the applied force by the number of $\mathrm{MN}$ in an array) to the force at which $\mathrm{MN}$ penetration into skin was observed. After removal of MN arrays, $30 \mu \mathrm{l}$ of methylene blue solution $\left(1 \mathrm{mg} \mathrm{ml}^{-1}\right)$ was applied to the upper surface $\left(0.5 \mathrm{~cm}^{2}\right)$ of the epidermis for 20 mins so MN created pores within the skin could be visualised. Excess solution was gently wiped off from the skin surface with dry tissue paper and then with normal saline solution. Subsequently, skin was imaged using a digital camera to assess for the presence of visible holes created by $\mathrm{MN}$ arrays.

\section{Theory}

\subsection{Mechanics of needle insertion into skin}

We start by comparing the process of single needle insertion with the insertion of two needles into the skin, thereby identifying the forces acting in both cases. These forces are then defined separately and estimated using applicable equations. The insertion process for a 
single needle into soft tissue has been defined as comprising of three main phases - stiffness, friction and cutting (Okamura et al, 2004).

The stiffness, cutting and friction forces will be dependent upon the type and nature of the tissue that the needle is being inserted into, and the estimation of these forces will also be dependent upon the modelling approach involved for the tissue evaluation (Okamura et al, 2004; Davis et al, 2004; Ankersen et al, 1999).

Whilst previous models have focused on modelling the insertion of a single needle into tissue, in reality most microneedle devices comprise of an array of multiple, regularly spaced needles. As such, in order to fully understand and predict the insertion process into skin, it is necessary that an appropriate model is employed to consider that the presence of multiple needles will contribute to additional forces involved in the insertion process. Thus, this will compensate for any variations that may exist for the insertion force of a single needle and the insertion of an array of MNs.

This study hypothesizes that MN interspacing, i.e. the distance at the base between two consecutive microneedles, will introduce additional forces that should be considered. Furthermore, the framework presented here assumes the following:

(1) The skin has been pre-stretched allowing minimal indentation prior to piercing and giving it enough rigidity to be modelled as a beam. Also, we treat skin as a liner material where the strains and displacements/deformations are small.

(2) The microneedles in an array are tightly packed such that no folding of the skin or rotation of the micrneedles occurs between the needles. Therefore the indentation is that due to the SC stretching to allow for the microneedles to insert.

(3) Only the piercing to the stratum corneum is being considered. This is due to the fact that the SC acts as the main barrier to $\mathrm{MN}$ insertion.

Under the listed assumptions, we define these forces as indentation (stiffness), cutting, bending, friction and buckling forces.

$$
F_{\text {insertion }}=F_{\text {bending }}+F_{\text {stiffness }}+F_{\text {buckling }}+F_{\text {friction }}+F_{\text {cutting }}
$$


The combination of these forces acting during needle insertion is shown in Figure 1, with the implications of each force being described in detail in the following section.

\subsubsection{Bending Forces}

Consider two MNs at a known distance apart; inserted into the skin such that the skin in the space between them is displaced vertically in the direction of the applied force. To represent this, the skin is modelled as a beam on an elastic foundation and, as the stratum corneum (SC) is much stiffer than the other layers of the skin, it is modelled as the beam (Thalmann et al, 2002). The lower layers of the skin are, therefore, represented as the elastic foundation. Since the aim here is to develop a quantitative basis to relate MN interspacing and insertion mechanism of MNs, each layer will be assumed to be homogeneous, isotropic and elastic (Kuwazuru et al, 2008). Prior to insertion, the skin is modelled as an infinitely long beam on an elastic foundation with two concentrated loads.

The bending equation accounts for the one dimensional bending of the skin along the vertical axis. To calculate the bending force the equation for a beam on an elastic foundation allows us to combine the bending force of the beam with the reaction of the foundation as the beam bends along its length (Astapov et al, 1994). Where $b=$ foundation width, $v=$ Poisson ratio, $E_{s}=$ young modulus of foundation, $E=$ Young modulus of SC, $I=$ moment of inertia of the cross section of $\mathrm{SC}$ and $\mathrm{C}_{3}$ and $\mathrm{C}_{4}$ are integration constants, the equation for the deflection curve of a beam under transverse loading is given as (Hetenyi, 1964; Astapov and Kornev, 1994)

$y=e^{-\lambda s}\left(C_{3} \cos \lambda s+C_{4} \sin \lambda s\right)$

Where $y$ is the deflection at a distance s from the needle, for a beam of unlimited length with a single concentrated load the solution becomes,

$\mathrm{y}=\frac{\mathrm{F}_{\text {bending }} \lambda}{2 \beta} \mathrm{e}^{-\lambda \mathrm{x}}(\cos \lambda \mathrm{x}+\sin \lambda \mathrm{x})$

The deflection $\mathrm{y}_{0}$ directly underneath the load, $\mathrm{P}$ is given by;

$y_{0}=\frac{p \lambda}{2 \beta}$

Where $\lambda$ is a notation for the following 
$\lambda=\sqrt[4]{\frac{\beta}{4 E I}}$

The modulus of foundation, $\beta$, is obtained from the equation introduced by Vesic (1963) and Cheng-Zhang (2009):

$\beta=\frac{0.95 E_{g}}{\left(1-v^{2}\right)}\left[\frac{E_{g} b^{4}}{\left(1-v^{2}\right) E I}\right]^{0.108}$

The procedure to obtain a value for bending force during the insertion of two MNs with an interspacing $\mathrm{S}$ at the tip, is as follows; the equation was solved for a single concentrated force and then the second concentrated force was superimposed, more specifically, the force required to cause the maximum deflection underneath the first needle was calculated by rearranging Equation (4). The initial deflection at distance $S$ where the next needle is placed is then calculated using Equation (3). The additional force required to cause the maximum deflection at distance $S$ is then calculated using equation 4 making $\mathrm{y}_{0}$ the initial deflection caused by the first needle. The two forces where averaged to calculate the force required by each needle to bend the skin to allow the vertical deformation prior to penetration (Astapov et al, 1994).

\subsubsection{Indentation (stiffness) force.}

Following the bending of the skin, the needle tip starts to compress the stratum corneum. The vertical force exerted by the needle tip causes deformation of the skin, leading to piercing. This is the displacement that takes place prior to the breaking of the bond between the skin fibres as the needle pierces through the skin structure. The stiffness model derived by Okamura et al. (2004) is based on the experimental condition employed; we use a more general model here to describe the force required for the needle to indent the skin before piercing. The force between the needle tip and skin surface during compression has been represented by Hertz as follows (Yuan and Verma, 2006);

$$
\mathrm{F}_{\text {indentation }}=\frac{4 \mathrm{E} \sqrt{\mathrm{r}}}{3\left(1-\mathrm{v}^{2}\right)} \delta^{3 / 2}
$$

where $\mathrm{E}$ is the elastic modulus, $\mathrm{r}$ is the tip radius of microneedle, $\mathrm{v}$ is the Poisson ratio and $\delta$ is the indentation depth 
This equation was obtained from analysing the force acting between a spherical indenter and the tip of the indenter (Yuan and Verma, 2006). As the main barrier is the stratum corneum, with the underlying layers having a much lower stress limit (Kuwazuru et al, 2008; Cua et al 1990), we take $\mathrm{E}$ and $\mathrm{v}$ to be the young modulus and Poisson ratio of the stratum corneum, respectively. The indentation depth is assumed to be $100 \%$ of the thickness of the stratum corneum, this is considering the fact that some compression also occur during cutting (Okamura et al, 2004). The Hertz model assumes the materials in contact are smooth and linearly elastic. The advantage of using this model is that it takes into account the shape of the needle tip.

\subsubsection{Cutting Force}

After the pre puncture forces (bending and indentation) have been applied to the skin, a force is required to cut through the tissue fibre, thus initiating MN penetration. Once the skin has been compressed to its minimum thickness, an additional force is required to enable the MN array to cut through the skin. The cutting force can be envisaged as the bond energy which integrates the tissue structure (Okamura et al, 2004). This energy must, therefore, be exceeded in order to puncture the skin. The cutting force is a constant and its value is determined by factors such as sharpness of the penetrant and the type and nature of the tissue under consideration (Davis et al, 2004; Okamura et al, 2004; Sharaf et al, 2003).

\subsubsection{Buckling Force}

As the needle cuts through the skin tissue the needle inserts into the stratum corneum. The skin between the needles must therefore buckle to allow for this insertion to occur; hence cutting and buckling occur simultaneously. The resistance offered by the lower layer of the skin as the SC buckles is represented by the foundation modulus (Kuwazuru et al, 2008).

The minimum force required to cause skin buckling depends on the interspacing between the needles. The force causing this deformation is the lateral force exerted by the needles on the skin; the beam in this case therefore has a finite length, $\mathrm{S}$ which is the interspacing between the MNs at the tips.

The minimum force ( $F_{\text {buckling}}$ ) required for causing skin buckling is an additional force necessary to insert an array of MNs at an interspacing $\mathrm{S}$ at the tip. This is given by Equation 8 (Timoshenko, 1936), 


$$
\mathrm{F}_{\text {buckling }}=\frac{2 \mathrm{~m}^{2} \pi^{2} \mathrm{EI}}{\mathrm{S}^{2}}
$$

Where $\mathrm{m}$ is the number of half sine wave of the bent bar which depends on the material properties and is given by:

$$
\mathrm{m}=\frac{\mathrm{S}}{\pi^{4} \sqrt{\frac{\mathrm{EI}}{\beta}}}
$$

The concept of buckling in the skin has previously been considered by Kuwazuru et al. (2008). The group applied a multistage buckling model to analyse the mechanism of wrinkle formation as a result of buckling of different layers of the skin, relative to age related changes in skin structure. The skin will deform linearly under relatively low stress (Diridollou et al, 2000, Fung, 1993), and in this study as we aim to quantify the effect of spacing on insertion force, the equations based on assumption of linear behaviour for a beam on an elastic foundation are adaptable for this purpose.

\subsubsection{Frictional force}

As the needle inserts into the skin, further resistance occurs in the form of friction generated as a result of the needle rubbing against the skin surface. Here the friction force was modelled using the equation presented by Okamura et al. (2004). The group obtained the damping coefficient by fitting the results from needle insertion experiments on liver tissue to Karnopp’s modified friction model (Kirnopp, 1985). The linear model obtained was solved to account for the friction force during needle insertion. The friction force is determined by the friction damping parameter $b_{p}$, the insertion depth $l[\mathrm{~m}]$ and the speed of insertion $\mathrm{v}\left[\mathrm{ms}^{-1}\right]$

$$
\mathrm{F}_{\text {Friction }}=\mathrm{b}_{\mathrm{p}} \mathrm{lv}
$$

In the following section we use the framework presented above to predict insertion force for different skin types and we show the effect of interspacing on insertion force. Two dimensional simulation of MNs inserted in the skin are used to show the effect of interspacing on skin deformation and stress at needle tip.

\subsubsection{Finite Element Modelling (FEM) modelling of MN insertion}


2D FEM simulations were performed for the numerical analysis of $\mathrm{MN}$ insertion into skin at various interspacing. The simulations were carried out using COMSOL (Comsol, 2005), modelling the skin as an isotropic elastic material with the aforementioned mechanical properties and the needles as tapered metallic structures made of titanium. COMSOL has been applied in previous studies for biomedical studies on microneedles (Al Qallaf et al, 2009). The software has a user friendly graphical interface that allows solution of contact problems in 1 to 3 -D mode. Plane stress analysis was carried out while assuming linear deformation of skin and microneedles and, the constitutive equation for linear materials is used to model the deformation of the skin given as:

$$
\bar{V} \cdot(-c \bar{V} \boldsymbol{u}-\alpha \boldsymbol{u}+\gamma)+a \boldsymbol{u}+\beta \cdot \bar{V} \boldsymbol{u}=f
$$

Where $\mathrm{c}, \alpha, \mathrm{a}, \beta$ are constants and $\gamma$ and $\mathrm{f}$ are source terms which depend on the boundary conditions imposed. In this particular case, $\mathrm{c}$ is the elasticity matrix consisting of poison ratio (v) and Young modulus (E), the values for these are discussed later. $\alpha$ is the stress tensor, $\gamma$ is the initial strain vector which is 0 in the simulations presented, a is the mass damping parameter $(1 \mathrm{Ns} / \mathrm{m}), \beta$ is the stiffness damping parameter $(0.01 \mathrm{~N} / \mathrm{m}), u$ is the vector of dependent variable such as displacement in this case $\mathrm{f}$ is the force term which is the load applied at the MN base as discussed in the following section. The boundary conditions are defined such that the base on which the skin is placed is rigid and the skin surface is movable in all direction. The solutions obtained from numerical simulations are discussed in section 4. It is known that the mechanical properties of skin vary with respect to different factors such as anatomical region, age, gender and individual phenotype (Escoffier et al, 1988; Cua et al, 1990; Agache et al, 2004; Gambichler et al, 2006). Yuan and Verma (2006) revealed that the Young modulus for stratum corneum of porcine skin was dependent upon the moisture content of the skin, ranging from $26-120 \mathrm{MPa}$, for wet and dry skin, respectively. It has been suggested that this range of values may be representative of how the mechanical properties of the skin varies with age. In particular, the lower value of Young modulus seen for wet skin may be taken to represent skin from a young adult, whilst the values for the dry skin may represent that of an elderly adult. As such, in the results presented in this paper we have applied our theoretical model to both the upper and lower limit of the reported young modulus values, applying the following assumptions. The Young modulus of the viable epidermis for skin from a young adult was assumed to be half of that from an elderly adult 
(Agache et al, 1980; Kuwazuru et al, 2008). Therefore, 0.272MPa was defined for the viable epidermis of an elderly adult since young modulus for epidermis of skin from a young adult has been reported as 0.136MPa (Maemo et al, 1997; Kuwazuru et al, 2008). The thickness of the viable epidermis also varies with age. The viable epidermis is approximately $51 \mu \mathrm{m}$ for a young adult and 37 $\mu \mathrm{m}$ for an elderly adult (Gambicher et al, 2006).

\section{Results and Discussions}

The results section is ordered in such a way that the results from FEM simulations are presented first, followed by results from theoretical analysis. In the final part of the result section the theoretical analysis is then compared with the experimental findings.

\subsection{FEM modelling of $M N$ insertion}

Stress and displacement values where obtained from the numerical simulations in COMSOL. Analysing the stress and displacement of the microneedles prior to insertion serves as a measure of resistance offered by the skin prior to insertion at various interspacing as discussed in the following subsections.

\subsubsection{Effect of interspacing on stress at MN Tip}

Simulations in 2-D were carried out using COMSOL, of MNs pressed against the skin surface with an equal predetermined force of $0.0027 \mathrm{~N}$ at the base of each needle (Figure 2). The upper layer, the stratum corneum was given a young modulus of 26MPa while the lower layer was given a young modulus of 136KPa (Yuan and Verma, 2006) and the Poisson ratio was taken as 0.49 for both layers (Magnenat-Thalmann, 2002). The interspacing was then varied between $25 \mu \mathrm{m}$ and $315 \mu \mathrm{m}$ increasing by $10 \mu \mathrm{m}$ for two different geometries. Figure 2 shows results obtained when the MNs were modelled as $400 \mu \mathrm{m}$ long tapered MNs with a base radius of $60 \mu \mathrm{m}$ and tip radius of $30 \mu \mathrm{m}$. This small geometry (relative to the MN sizes used in the experiment) has been used in order to achieve close interspacing at the tip and this allows us to obtain a wider range of results, prior to experimental verification of the proposed model, which was adjusted to match the shape and dimensions of the MN arrays used in the study. The stress at the MN tips was calculated for 30 different values of interspacing. The results shown in Figure 3 indicate a decrease in stress at MN tip as the interspacing is increased. 
In another simulation a row of 3 microneedles attached to an array with an applied load of $0.00576 \mathrm{~N}$ was inserted into skin using the same MN geometry and skin properties listed above. The normal stress on each MN was then obtained as an average of normal stress on all three MNs (Figure 4a). This was then repeated for the microneedle geometry that has been used in the in vitro insertion experiment Figure 4b. The results, as shown in Figures 4a and 4b, indicate higher normal stress on the MNs at small interspacing and lower normal stress at wider interspacing. These results are in line with our proposed theory since the decrease in stress at the tip indicates that the MNs face less resistance as the needles are placed farther apart.

\subsubsection{Vertical Displacement of MNs prior to insertion}

The vertical displacement of the needle acts as an indicator of the manner in which the skin deforms as a result of lateral stress distribution. A force of $2.7 \mathrm{~N}$ was applied at the base of each needle and the vertical displacement of the needles was measured for different interspacing (Figure 5). The results show a decrease in vertical displacement as the interspacing increases, with a sharper decrease between 10 and $150 \mu \mathrm{m}$. This may be explained by the fact that the stress distribution around each needle intercept becomes less as the interspacing increases (compare Figures 2).

\subsection{Insertion force estimation}

First we calculate the bending, indentation, cutting, buckling and friction forces separately at different MN interspacing. The total insertion force is then estimated based on the presented framework. The parameters for 'old' and 'young' skin have been used here for the purpose of comparing two different types of skin. In order to assess the validity of the results suggested by the model, a series of in vitro experiments were conducted to determine the insertion force for conical shaped MNs of $600 \mu \mathrm{m}$ height and $300 \mu \mathrm{m}$ width at base, with varying MN interspacing distances. These experimental results were then compared with the theoretical values.

\subsubsection{Bending Forces}

Using equations 3 - 6, the bending force was calculated for a range of varying $\mathrm{MN}$ interspacing. The results, as shown in Figure 6, predict that the force required to bend the skin before puncture will increase as the spacing between the needles increases, showing a much steeper increase for lower interspacing. Bending force for the skin of an elderly adult 
(termed "aged” skin) is higher than that for the skin of a young adult (termed "young” skin). This is expected due to the difference in the mechanical properties of the skin as a function of age (Agache et al, 1980).

\subsubsection{Indentation Force.}

The force required for the needle to indent the surface of the stratum corneum before piercing through is calculated using Equation 7. Using a tip radius of 15 microns the indentation force estimated for young skin was $0.007345 \mathrm{~N}$, and for older skin $0.047375 \mathrm{~N}$. The needle was assumed to compress the stratum corneum by $60 \%$ of its thickness prior to insertion. This assumption is based on the theory that skin consists of pore spaces (Tezel, 2002) such that the compression causes realignment of the skin fibre (Leddy and Guilak 2008; Leddy et al, 2006) causing the spaces to close. The indentation force is not affected by interspacing, however it should be included in the total insertion force calculation.

\subsubsection{Cutting Force}

The theoretical pressure to pierce human skin is reported as $3.183 \times 10^{6} \mathrm{~Pa}$ (Aggarwal and Johnston, 2004). However this force is a combination of pre puncture and post puncture forces. Okamura (2004) isolated the forces during needle insertion into liver tissue and obtained a cutting force of $0.94 \mathrm{~N}$ for a needle with tip diameter of $1.27 \mathrm{~mm}$ at a speed of $0.003 \mathrm{~m} \mathrm{~s}^{-1}$. By calculating the kinetic energy, the pressure of insertion was obtained and in turn used to approximate the insertion force for a $\mathrm{MN}$ with a tip radius of $15 \mu \mathrm{m}$ giving a value of $0.019 \mathrm{~N}$. This force is assumed to be instantaneous and independent of depth and is the same for young and old skin. However, as these experiments were performed on bovine liver tissue, the value determined by this model is used here only as an estimate for MN penetration into skin.

\subsubsection{Buckling Force}

The skin is modeled as a beam on an elastic foundation under two axial loads to obtain the minimum force required to buckle the skin at different spacings between the loads. The analysis predicts a general decrease in the buckling force as the interspacings at the needle tips increase for both old and young skin (Figure 7). The oscilating nature of the result suggests an optimum value within a given range but in general buckling force decreases as interspacing increases. 


\subsubsection{Frictional force}

The frictional force, like the indentation and cutting forces, is independent of interspacing. The distance travelled by the needle 1 , in this case is the thickness of the skin before puncture which is assumed to be $40 \%$ of the original thickness of the stratum corneum. The friction force values obtained here is relatively low, for example from our calculations using equation 10 , at $0.5 \mathrm{~mm} / \mathrm{s}$ the estimated friction force is $5.03 \mu \mathrm{N}$.

\subsubsection{Total insertion force}

Summing up these forces gives the total force required to insert each MN having accounted for the effect of the MN interspacing. Theoretical analysis indicates that the cutting force accounts for much of the MN penetration, whilst the bending force of the skin contributes the least. The total insertion forces at different interspacing are plotted in Figure 8 showing a combined effect of MN interspacing on bending and buckling forces. At lower spacing the effect of interspacing on insertion force should be more noticeable, and as the spacing increases, the effect on insertion force becomes less prominent or almost absent.

The interspacing between the needles has an effect on the buckling and bending force but no effect on the indentation, friction and cutting forces. Therefore, to obtain a direct relationship between insertion force and interspacing, regression analysis was carried out on the variable forces (bending and buckling). Regression analysis of Figure 8 shows the effect of interspacing on insertion force to be well represented by a power law equation $\left(\mathrm{R}^{2}=0.63\right)$ of the form in equation (12). $F_{\text {bending+buckling }}$ is the sum of the bending and buckling force per unit area for each microneedle, a and b are constants that are obtained by fitting the equation with experimental values as discussed in the following sections.

$F_{\text {bending }+ \text { buckling }}=a S^{-b}$

\subsubsection{In vitro determination of insertion force required for $M N$ penetration into neonatal} porcine skin using texture anlayser.

In order to assess the validity of the proposed mathematical model, a series of in vitro experiments were performed to determine the force required for $\mathrm{MN}$ insertion into neonatal porcine skin for $\mathrm{MN}$ arrays with varying $\mathrm{MN}$ interspacing. The polymeric $\mathrm{MN}$ arrays employed within this study were conical in shape, with a MN height of $600 \mu \mathrm{m}$ and base 
width of $300 \mu \mathrm{m}$. The laser-engineering process used during the production of these MNs, enabled arrays of MN interspacing from 30-600 $\mu \mathrm{m}$ to be designed for testing. The experimental data for the determination of $\mathrm{MN}$ insertion force into excised neonatal porcine skin were analysed using a one-way analysis of variance (ANOVA), with post hoc comparisons performed using Tukey's HSD test. In all cases, $p<0.05$ denoted significance. It was found that for all MN interspacing values, the speed at which they were inserted had a significant effect $(p<0.001)$ upon the force required for MN insertion. In particular, an increase in the speed at which MN were applied to the skin surface resulted in a decrease in the force required for insertion into the skin. It can be seen from Table 2 that the force required for $\mathrm{MN}$ insertion ranged from 0.0216 N/MN to 0.0214 N/MN at an insertion speed of $1.0 \mathrm{~mm} \mathrm{~s}^{-1}$, and $0.03 \mathrm{~N} / \mathrm{MN}$ to $0.028 \mathrm{~N} / \mathrm{MN}$ at an insertion speed of $0.5 \mathrm{~mm} \mathrm{~s}^{-1}$ for a MN array of interspacing $30 \mu \mathrm{m}$ and $>150 \mu \mathrm{m}$, respectively. This is in agreement with previously reported findings, where it has been shown that the use of a high velocity (1-3 $\left.\mathrm{m} \mathrm{s}^{-1}\right)$ applicator enabled more reproducible $\mathrm{MN}$ insertion into dermatomed human skin when compared to manual MN insertion (Verbaan et al, 2008). It has been suggested that the natural elasticity of the skin may counteract the penetration of MNs into the skin when the MNs are inserted slowly into the skin (Verbaan et al, 2008; Crichton et al, 2010). Furthermore, it has been shown that increasing the velocity of MN application led to an increase in the transport rate of a model compound, cascade blue, across dermatomed human skin (Verbaan et al, 2008). This suggests that the speed of application is important for both the insertion and penetration of MNs into the skin. In regards to the effect of MN interspacing upon the force required for MN insertion into skin, it was found that only the MN arrays with interspacing values $\leq 50 \mu \mathrm{m}$ had a significantly different $(p<0.001)$ insertion force per $\mathrm{MN}$, in comparison to the arrays of MN interspacing 150-600 $\mu \mathrm{m}$. Whilst it has been shown that increasing the density of a $\mathrm{MN}$ array can led to an increase in the rate of transdermal drug delivery (Oh et al, 2008; Yan et al, 2010), it appears that there will be an optimum density for any given MN design and application (Widera et al, 2006; Verbaan et al, 2008; Yan et al, 2010). Yan et al, (2010) observed lower drug permeation results for very high MN array densities ( $>20,000 \mathrm{MN} \mathrm{cm}^{2}$ ). This was attributed to the fact that each MN array was inserted at the same force per unit area (44.5 N), rather than the same force per actual MN, such that the depth of penetration of these high density arrays may have been reduced in comparison to arrays of lower MN density. To ensure that the forces determined here would be applicable to an array with a larger number of MN, but the same MN interspacing, confirmation studies were performed to assess if a force of $0.0214 \mathrm{~N} / \mathrm{MN}$ would enable successful skin insertion of 
a MN array with 121 MNs (MN height $600 \mu \mathrm{m}$, MN width $300 \mu \mathrm{m}$ and MN interspacing 300 $\mu \mathrm{m})$. This confirmed that the insertion force was dependent upon MN interspacing and not MN number, with the same insertion force per MN required to insert a MN array with 9 MNs in total and an array with 121 MNs (i.e. insertion force of $0.0214 \mathrm{~N} / \mathrm{MN}$ at a speed of 1.0 $\mathrm{mm} / \mathrm{s}$ ). Representative digital images used as confirmation of $\mathrm{MN}$ insertion are shown in Figure 9. These experimental findings are in agreement with the predictions based upon the theoretical model proposed within this study (Figure 8) as the results show a decrease in insertion force as the interspacing is increased. Further analysis are carried out to obtan a quantitative relationship between interspacing and insertion force. This is discussed in the next section.

\subsubsection{Tuned Model based on experiment Results}

To obtain a direct relationship between insertion force and interspacing, regression analysis was carried out on the results based on the theoretical analysis. The buckling and bending forces at each interspacing was summed up and plotted against corresponding interspacing to obtain a direct relationship between additional forces required for insertion due to interspacing. The constant forces (cutting, friction and stiffness) for a given MN geometry are then added to this force to obtain total insertion force. From regression analysis, the effect of interspacing on insertion force $\mathrm{F}$ was best described by a Power law equation of the form:

Where $\mathrm{F}$ is the force applied at the needle base $(\mathrm{N})$. This derived equation was then tuned with the experimental results (Table 2) obtained given the following equation for additional force required due to interspacing as:

$$
F_{\text {bendingtbuckling }}=2.538 x^{-1.289}
$$

The force is divided by the area of the MN base to give the force per unit area such that the total force per unit area (KPa) per MN can be expressed as:

$F_{\text {insertion }}=F_{\text {cutting }}+\frac{4 E \sqrt{r}}{3\left(1-v^{2}\right)} \delta^{3 / 2}+b_{p} l v+35905 x^{-1.289}$

The model results presented here (Figure 10) is valid within the range 30 to $150 \mu \mathrm{m}$ interspacing at $\mathrm{MN}$ base since the experimental results show no variation in insertion force beyond $150 \mu \mathrm{m}$. In addition to this, since the skin property varies for different species and 
sites of the body, it should be considered that Equation 14 is derived from experiments carried out on neonatal porcine skin.

\section{Conclusion}

In this study, we have presented experimental results and theoretical analysis which provide a quantitative basis for relating the arrangement of MNs in terms of interspacing with the insertion force of MNs. The results indicate that the framework is useful in calculating insertion force and the predicted pattern is comparable with experimental results. This model is expected to be useful for planning the optimum design of a MN device, with consideration given to maximising the number of MNs within a given area in order to enhance the rate of drug delivery whilst negating against any potential "bed of nails” effect. Furthermore, by predicting the minimum force required for $\mathrm{MN}$ insertion this model may aid in the development of an appropriate applicator for reproducible MN penetration into skin.

\section{References}

Al-Qallaf, B., Das, D.B. (2008). Optimization of Square Microneedle Arrays for increasing Drug Permeability in Skin. Chemical Engineering Science, Chemical Engineering Science, 63, 2523 2535.

Al-Qallaf, B., Das, D.B. (2009a). Optimizing Microneedle Arrays for Transdermal Drug Delivery: Extension to Non-square Distribution of Microneedles. Journal of Drug Targetting, 17(2), 108-122.

Al-Qallaf, B., Das, D.B. (2009b). Optimisation of Micro-needle Arrays to increase Skin Permeability for Transdermal Drug Delivery. Annals of the New York Academy of Sciences, 1161, 83-94, doi:10.1111/j.1749- 6632.2009.04083.x

Al-Qallaf, B., Mori, D., Olatunji, O., Das, D.B., Cui, Z.F. (2009a). Transdermal Drug Delivery by Coated Microneedles: Does Drug Metabolism Matter? International Journal of Chemical Reactor Engineering, 7, article A69.

Al-Qallaf, B., Das, D.B., Davidson, A. (2009b). Transdermal Drug Delivery by Coated Microneedles: Geometry Effects on Drug Concentration in Blood. Asia-Pacific Journal of Chemical Engineering, $4(6), 845$ - 857. 
Al-Qallaf, B., Das, D.B., Mori, D., Cui, Z.F. (2007). Modelling Transdermal Delivery of High Molecular Weight Drugs from Micro-needle Systems. Philosophical Transactions of the Royal Socociety. Part A. doi:10.1098/rsta.2007.0003

Aggarwal P, Johnston CR. (2004) Geometrical effects in mechanical characterizing of microneedle for biomedical applications. Sens. Act. B. 102, 226-234

Agache P., Humbert P. (2004) Measuring the skin. Berlin: Springer.

Agache, P., Monneur, C., Leveque, L.J., De Rigal, J. (1980) Mechanical Properties and Young's Modulus of Human Skin in Vivo. Archives of Dermatological Research. 269, 221-232.

Azar, T., Hayward, V., (2008) Estimation of the Fracture Toughness of Soft Tissue From Needle Insertion, Proceedures on Biomedical Simulation, 4th International Symposium. 5104, 166-175.

Ankerson J. Birkbeck, A.E, Thomson, R. D., Vanezis, P., (1999) Puncture resistance and tensile strength of skin stimulants. Proc Institute of Mechanical Engineering. 213(Part H):493-501.

Astapov, N.S., Kornev, V.M., (1994) Postbuckling behaviour of an Ideal Bar on an Elastic Foundation. Journal of Applied Mechanics and Technical Physics. 35(2), 286-296.

Comsol, A.B. (2005). Comsol@ 3 multiphysics modelling, Documentation, Comsol AB., Stockholm, Sweden.

Crichton ML, Ansaldo A, Chen X, Prow TW, Fernando GJP, Kendall MAF. (2010). The effect of strain rate on the precision of penetration of short densely packed microprojection array patches coated with vaccine. Biomaterials. doi: 10.1016/j.biomaterials.2010.02.022

Cheng-Zhong, Q., Ping, S., (2009) An improved Method for foundation modulus in highway engineering. EDJE, 14, 1- 12.

Cua, A.B, Wilhelm, K.P., Maibach, H.i. (1990) Frictional properties of human skin: relation to age, sex and anatomical region, stratum corneum hydration and transepidermal water loss. Gritish Journal of Dermatology. 123(4). 473-479.

D. d'Aulignac, R. Balaniuk, and C. Laugier, 2000, A haptic interface for a virtual exam of the human thigh. Proceedings of IEEE International Conference on Robotics and Automation, 2452-2456. 
Davidson, A., Al-Qallaf, B., Das, D.B. (2008). Transdermal Drug Delivery by Coated Microneedles: Geometry Effects on Effective Skin Thickness and Drug Permeability. Chemical Engineering Research and Design, 86, 1196-1206.

S. P. DiMaio and S. E. Salcudean, (2002). Needle insertion modelling and simulation, in Proc. IEEE Int. Conf. Robotics Automat. 2098-2105.

DiMaio, S.P., Salcudeanm S.E. (2003) Needle Insertion Modelling and Simulation. IEEE Transactions on Robotics and Automation:L Special Issue on Medical Robotica.

DiMaio SP, Salcudean SE. (2005) Interactive simulation of needle insertion models. IEEE Transactions in Biomedical Engineering;52(7):1167-79.

Davis, S.P, Landis, B.J, Adams, Z.H, Allen, M.G, Prausnitz, M.R. (2004). Insertion of microneedles into skin: measurement and prediction of insertion force and needle fracture force. J Biomechanics. 37, 1155-1163

Donnelly RF, Garland MJ, Morrow DIJ, et al. (2010). Optical coherence tomography is a valuable tool in the study of the effects of microneedle geometry on skin penetration characteristics and in-skin dissolution J. Cont. Rel. 147, 333-341

Donnelly RF, Majithiya R, Singh TRR, et al. (2011). Design, optimization and characterisation of polymeric microneedle arrays prepared by a novel laser-based micromoulding technique. Pharm. Res. 28, 41-57

Diridollou S, Black D, Lagarde JM, Gall Y, Berson M, Vabre V, et al. (2000). Sex- and sitedependent variations in the thickness and mechanical properties of human skin in vivo. International Journal of Cosmetic Science. 22:421-35.

Escoffier, C., Rigal, J., Rochefort, A., VAseselet, R., Leveque, J., Agache P.G. (1989), Age-Related Mechanical Properties of Human SKin: An In Vivo Study. Journal of Investigative Dermatology. DOI 0022-202X/89/S03.50

Egawa, M., Hirao, T., Takahashi, M., (2007) In vivo estimation of stratum corneum thickness from water concentration profiles obtained with Raman spectroscopy. Acter Derm Venereol. 87, 4-8. 
Fung, Y. C. (1993): Biomechanics: Mechanical Properties of Living Tissues, Springer-Verlag, New York 1993, 242-320.

Fourtanier, A., Berrebi, C. (1989) Miniature Pig as an Animal Model to Study Photoaging. Photochemistry and Photobiology DOI:10.1111/j.1751-1097.1989.tb02908.x. 50(6), 771-784.

Fung, Y.C. (1993). Biomechanics: Mechanical properties of Living Tissues, $2^{\text {nd }}$ ed. New York: Springer-Verlag,

Gambichler, T., Matip, R., Moussa, G., Altmeyer, P., Hoffmann, K. (2006) In vivo data of epidermial thickness evaluated by optical coherence tomography: Effects of age, gender, skin type and anatomical site. 44, 145-152.

Gammal, C. A.M. Kligman, S. Gammal, K.-P. Wilhelm, P. Elsner, E. Berardesca, H.I. Maibach. (1997). Bioengineering of the Skin: Skin Surface Imaging and Analysis, CRC Press, Boca Raton, 319 (Part 1).

Henry S, McAllister DV, Allen MG, (1998). Prausnitz MR. Microfabricated microneedles: a novel approach to transdermal drug delivery. Journal of Pharmaceutical Science. 87, 922-925.

Holbrook, K. A, Odland, G. M., (1974) Regional differences in the thickness (cell layers) of the human stratum corneum: an ultrastructural analysis. Journal of investigative dermatology. 62, 415422.

Hetenyi, M. (1948). A General Solution for the Bending of Beamsa on an Elastic Foundation of Arbitrary Continuity. Paper Presented at the VII International Congress of Applied Mechanics. London, England, September 5-11. 21, 55-58.

Karnopp D. (1985). Computer simulation of stick-slip friction in mechanical dynamic systems. Trans ASME Journal of Dynamic Systems Measurement and Control. 107:100-3.

Kuwazuru, O., Saothong, J., Yoshikawa, N., (2008) Mechanical approach to aging and wrinkling of human facial skin based on the multistage buckling theory. Medical Engineering and Physics. 30, 516-522.

Leddy, H. A., M. A. Haider, and F. Guilak. (2006). Diffusional anisotropy in collagenous tissues: fluorescence imaging of continuous point photobleaching. Journal of Biophysics, 91, 311-316. 
Leddy, H. A., Guilak, F., (2008). Site-Specific Effects of Compression on Macromolecular Diffusion In Articular Cartilage, Biophysics Journal, 95, 4890-4895.

Maeno T, Kobayashi K, Yamazaki N. (1997). Relationship between structure of finger tissue and location of tactile receptors. Trans Japan Society of Mechanical Engineering. 63C:881-8.

Magnenat-Thalmann N, Kalra P, L'ev^eque JL, Bazin R, Batisse D, Querleux B. (2002). A computational skin model: fold and wrinkle formation. IEEE Trans Inf Technol Biomed. 6:317-23.

Mahvash , M., Hayward, V. (2001). Haptic Rendering of Cutting: a Fracture Mechanics Approach. Haptics-e 2,

Maurin, B., L. Barb’e, B. Bayle, P. Zanne, J. Gangloff, M. de Mathelin, A. Gangi and A. Forgionne (2004). In vivo study of forces during needle insertions. In: Scientific Workshop on Medical Robotics, Navigation and Visualization. Remagen, Germany. 415-422.

Okamura, A.M et al. Force modelling for needle insertion into soft tissue. (2004). IEEE Transactions in Biomedical Engineering. 51(10):1707-16.

Oh JH, Park HH, Do KY, et al. (2008). Influence of the delivery systems using a microneedle array on the permeation of a hydrophilic molecule, calcein. Eur.J.Pharm.Biopharm. 69, 1040-1045.

Olatunji, O, Das, DB, Nassehi, V (2012). Modelling transdermal drug delivery using microneedles: Effect of geometry on drug transport behaviour. Journal of Pharmaceutical Sciences, 101 (1), 164175.

M. P. Ottensmeyer and J. K. Salisbury. (2001). "In vivo data acquisition instrument for solid organ mechanical property measurement,” in Proceedings of the 4th Int. Conf. Med. Image Computing Computer-Assisted Intervention, 975-982.

Prausnitz M.R., (2004). Microneedles for transdermal drug delivery. Advanced drug delivery reviews. 56 (5); pp.581-587.

Prausnitz MR. (2004). Microneedles for transdermal drug delivery Advanced Drug Delivery Review. $56,581-587$. 
J. Rosen, B. Hannaford, M. MacFarlane, and M. Sinanan, (1999). "Force controlled and teleoperated endoscopic grasper for minimally invasive surgery-Experimental performance evaluation,” IEEE Trans. Biomed. Eng., vol. 46, pp. 1212-1221.

Sharaf,R., Aggarwal, P., KaranV.I.S. Kaler and Wael Badawy. (2003). On the Design of an Electronic Mosquito: Design and Analysis of the Micro-needle, Proceedings of the International Conference on MEMS, NANO and Smart Systems. 0-7695-1947-4/03.

Simone, C., Okamura, A. (2002). Haptic Modelling of Needle insertion for Robot-Assisted Percutaneus Therapy. Proceedings of the IEEE International Conference on Robotica and Automation, May.

Simone C. (2002). Modelling of needle insertion forces for percutaneous therapies. Master's thesis. Baltimore, MD, USA: Johns Hopkins University.

Timoshenko, S. (1961) Theory of Elastic Stability. McGraw-Hill Book Company, Inc. New York and London. $1^{\text {st }}$ Ed. 108-111.

Takema, Y., Yorimito, Y., Kawai, M., Imokawa, G. (1994) Age-related changes in the elastic properties and thickness of human facial skin. British Journal of Dermatology. 131(5), 641-8

Vesic, A.B. (1963) Beams on Elastic Subgrade and the Winkler's Hypothesis. Proceedings, 5th International Conference of Soil Mechanics, pp. 845 850.

Verbaan F.J., Bal S.M., Van den D.J.B., et al. (2008). Improved piercing of microneedle arrays in dermatomed human skin by an impact insertion method. Journal of Controlled. Release 128, 80-88.

Widera G, Johnson J, Kim L, et al. (2006). Effect of delivery parameters on immunization to ovalbumin following intracutaneous administration by a coated microneedle array patch system, Vaccine. 24, 1653-1664

Woolfson AD, McCafferty DF, McCallion CR, McAdams ET, Anderson J. (1995). Moistureactivated electrically conducting bioadhesive hydrogels as interfaces for bioelectrodes: effect of film hydration on cutaneous adherence in wet environments. J.Appl.Polym.Sci. 58, 1291-1296 
Yuan, Y., Verma, R., (2006). Measuring the microelastic properties of stratum corneum. Colloids and Surfaces B: Biointerfaces 48, 6-12

Yuan, Y., Verma, R., (2006). Measuring microelastic properties of stratum corneum. Coloids and surfaces B. 48, 6-12.

Yan G, Warner KS, Zhang J, Sharma S, Gale BK. (2010). Evaluation of needle length and density of microneedle arrays in the pretreatment of skin for transdermal drug delivery. International Journal of Pharmaceuticals. 391, 7-12

Yan, Kaiguo; Podder, T.; Li, L.; Joseph, J.; Rubens, D. R.; Messing, E. M.; Liao, L.; and Yu, Y., (2009). "A real-time prostate cancer detection technique using needle insertion force and patientspecific criteria during percutaneous intervention" (2009). Department of Radiation Oncology Faculty Papers. Paper 8. http://jdc.jefferson.edu/radoncfp/8 


\section{List of Figures}

Figure 1. Diagrammatic representation of a microneedle array and its geometrical parameters (a) Height of MN in array (b) Interspacing of MN base (c) Width of MN in array

Figure 2. Simulation results for strain showing microneedles inserted into a two layer model of skin. Results are for A) $10 \mu \mathrm{m} \mathrm{B)} 300 \mu \mathrm{m}$ interspacing and C) principal strain for $10 \mu \mathrm{m}$ interspacing

Figure 3. Stress at microneedle tip for different inter-spacing. a) $35 \mu \mathrm{m}$ to $305 \mu \mathrm{m} \mathrm{b}) 10 \mu \mathrm{m}$ to $305 \mu \mathrm{m}$

Figure 4. Normal stress on (a) microneedle geometry used within the in vitro insertion force determination experiments. (b) Theoretical MN design of $400 \mu \mathrm{m}$ height and a smaller wall angle than the polymeric conical shape MNs employed in the experimental section.

Figure 5 The vertical displacement decreases as the spacing is increased indicating that spacing has a significant impact on the manner in which skin deforms.

Figure 6 The force required to cause skin bending as a function of MN interspacing.

Figure 7. Buckling and bending force ( $F_{\text {buckling+bending }}$ ) at different interspacing of microneedles (S)

Figure 8. Effect of MN interspacing on the force required MN insertion into skin

Figure 9. Representative digital images highlighting the penetration of a $\mathrm{MN}$ array with 4 MNs / array on the left, and 121 MNs / array on the right.

Figure 10. Buckling and bending force ( $F_{\text {buckling+bending }}$ ) at different interspacing of microneedles (S) 


\section{List of Tables}

Table 1. Geometries of PMVE/MA MN arrays produced using laser engineered micromoulds.

Table 2. Experimental determination of the force required for successful MN penetration, as a function of MN interspacing and the speed of MN insertion. 
Table 1. Geometries of PMVE/MA MN arrays produced using laser engineered micromoulds.

\begin{tabular}{|c|c|c|c|c|c|}
\hline $\begin{array}{l}\text { MN } \\
\text { Type }\end{array}$ & $\begin{array}{c}\text { Height } \\
\text { ( } \mu \mathrm{m})\end{array}$ & $\begin{array}{l}\text { Width at base } \\
\qquad(\mu \mathrm{m})\end{array}$ & $\begin{array}{c}\text { Interspacing at base } \\
(\mu \mathrm{m})\end{array}$ & $\begin{array}{c}\text { Interspacing at tip } \\
(\mu \mathrm{m})\end{array}$ & $\begin{array}{l}\text { MN / } \\
\text { array }\end{array}$ \\
\hline 1 & 600 & 300 & 30 & 330 & 16 \\
\hline 2 & 600 & 300 & 50 & 350 & 16 \\
\hline 3 & 600 & 300 & 150 & 450 & 9 \\
\hline 4 & 600 & 300 & 300 & 600 & 9 \\
\hline 5 & 600 & 300 & 600 & 900 & 4 \\
\hline
\end{tabular}


Table 2. Experimental determination of the force required for successful MN penetration, as a function of MN interspacing and the speed of MN insertion.

\begin{tabular}{|c|c|c|c|c|}
\hline \multirow{4}{*}{$\begin{array}{c}\text { MN } \\
\text { interspacing }\end{array}$} & \multicolumn{4}{|c|}{ Velocity of insertion } \\
\hline & \multicolumn{2}{|c|}{$0.5 \mathrm{~mm} \mathrm{~s}^{-1}$} & \multicolumn{2}{|c|}{$1.0 \mathrm{~mm} \mathrm{~s}^{-1}$} \\
\hline & \multicolumn{2}{|c|}{ Insertion Force } & \multicolumn{2}{|c|}{ Insertion Force } \\
\hline & (N/MN array) & $(\mathrm{N} / \mathrm{MN})$ & (N/MN array) & $(\mathrm{N} / \mathrm{MN})$ \\
\hline & $0.4800 \pm$ & $0.0300 \pm$ & $0.3456 \pm$ & $0.0216 \pm$ \\
\hline \multirow[t]{2}{*}{30} & 0.0017 & 0.0001 & 0.0002 & 0.00001 \\
\hline & $0.4648 \pm$ & $0.0291 \pm$ & $0.3442 \pm$ & $0.0215 \pm$ \\
\hline \multirow[t]{2}{*}{50} & 0.0023 & 0.0001 & 0.0003 & 0.00001 \\
\hline & $0.2524 \pm$ & $0.0280 \pm$ & $0.1926 \pm$ & $0.0214 \pm$ \\
\hline \multirow[t]{2}{*}{150} & 0.0017 & 0.0002 & 0.0001 & 0.00001 \\
\hline & $0.2524 \pm$ & $0.0280 \pm$ & $0.1926 \pm$ & $0.0214 \pm$ \\
\hline \multirow[t]{2}{*}{300} & 0.0019 & 0.0002 & 0.0002 & 0.00001 \\
\hline & $0.1122 \pm$ & $0.0280 \pm$ & $0.0856 \pm$ & $0.0214 \pm$ \\
\hline 600 & 0.0014 & 0.0003 & 0.0001 & 0.00001 \\
\hline
\end{tabular}




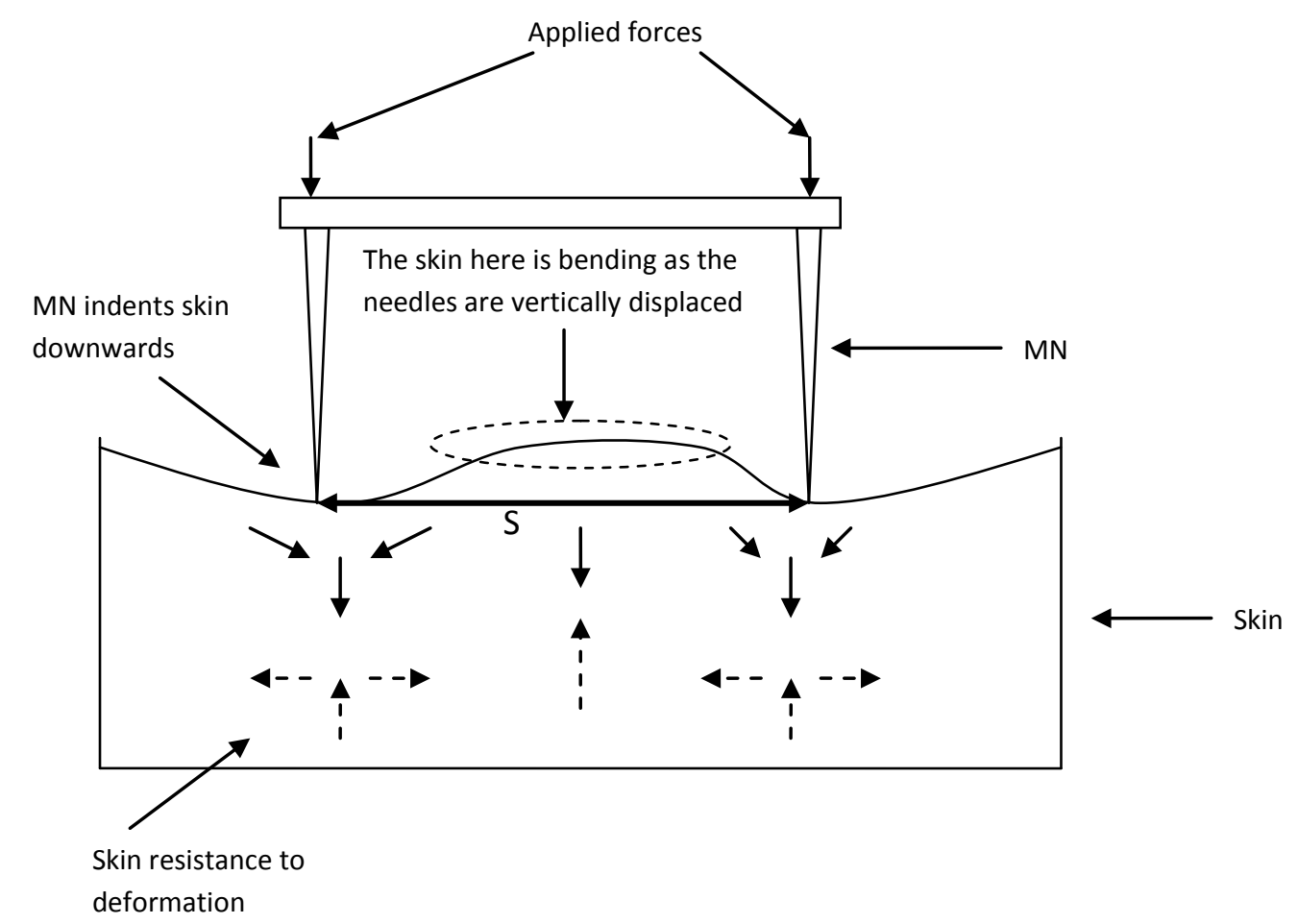

Figure 1. The forces in various directions acting on the skin during needle insertion prior to piercing 


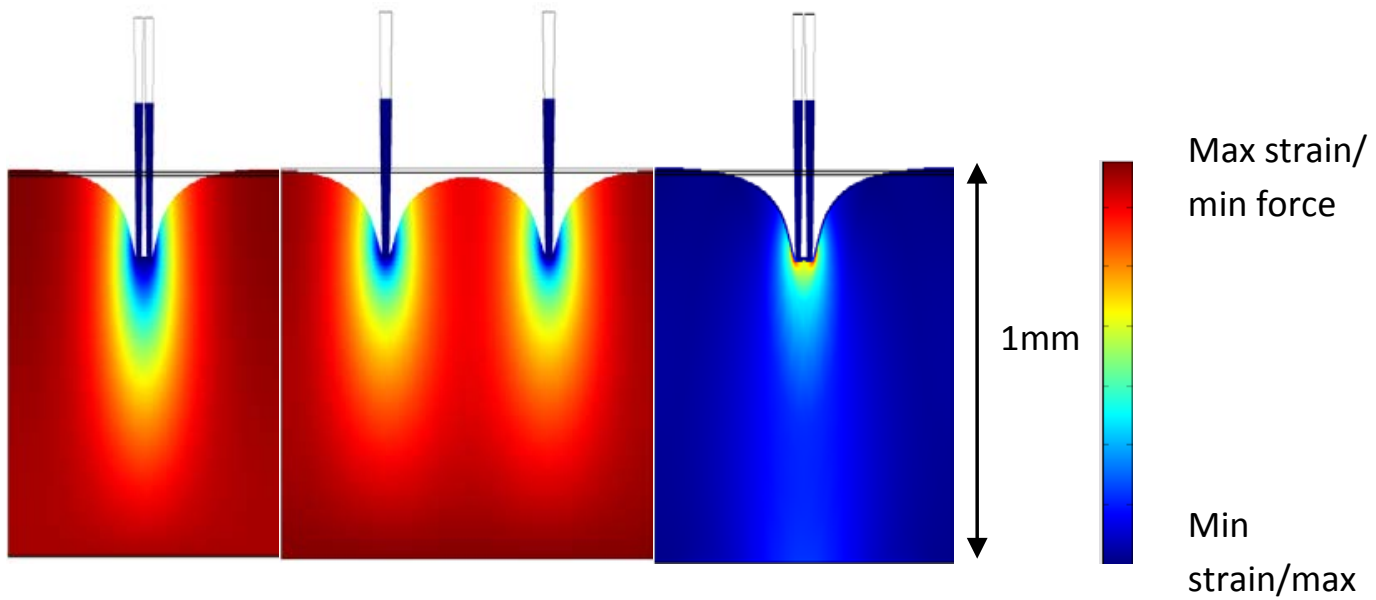

Figure 2 Simulation results for strain showing microneedles inserted into a two layer model of skin. Results are for A) $10 \mu \mathrm{m} \mathrm{B)} 300 \mu \mathrm{m}$ interspacing and C) principal strain for $10 \mu \mathrm{m}$ interspacing 


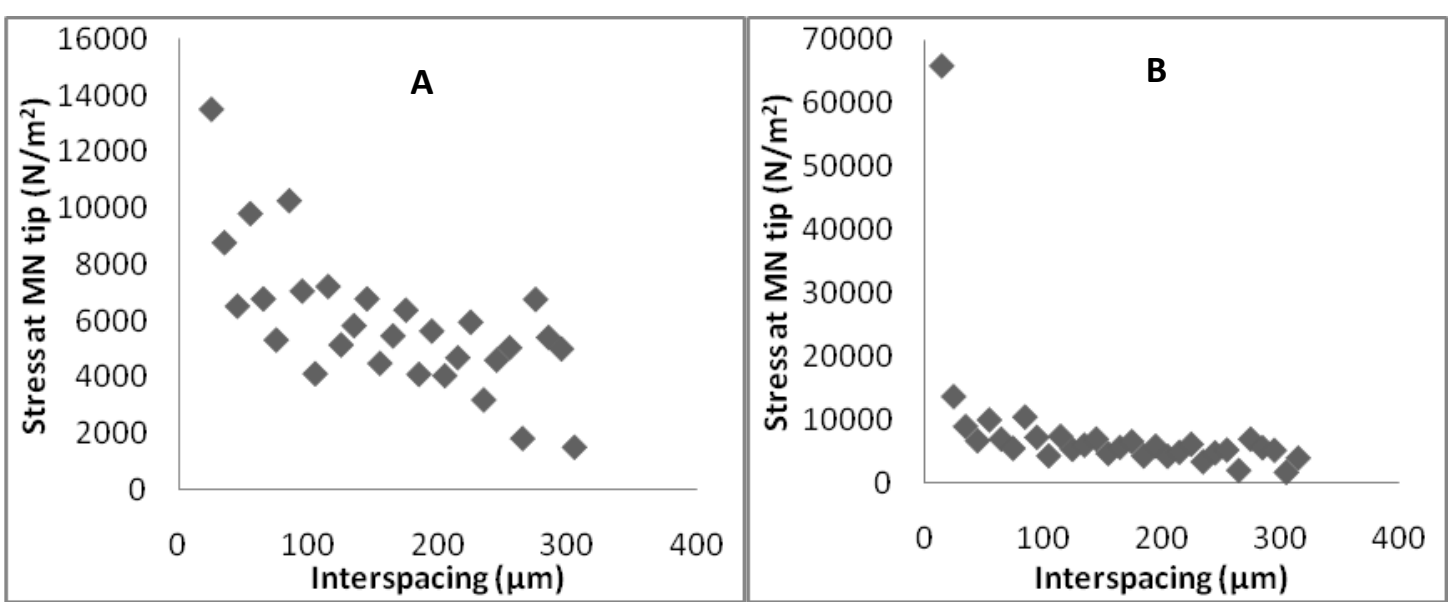

Figure 3 Stress at microneedle tip for different inter-spacing: a) $35 \mu \mathrm{m}$ to $305 \mu \mathrm{m} \mathrm{b}) 10 \mu \mathrm{m}$ to $305 \mu \mathrm{m}$ 


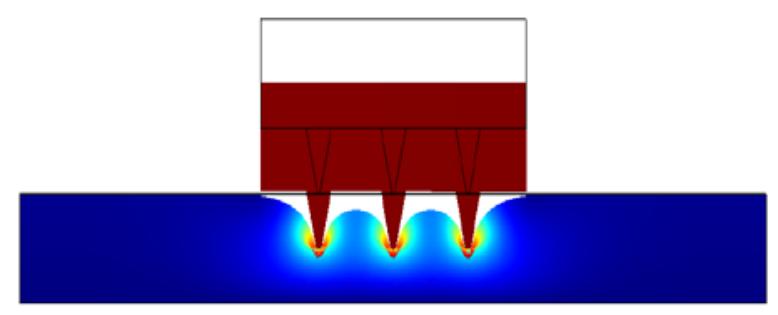

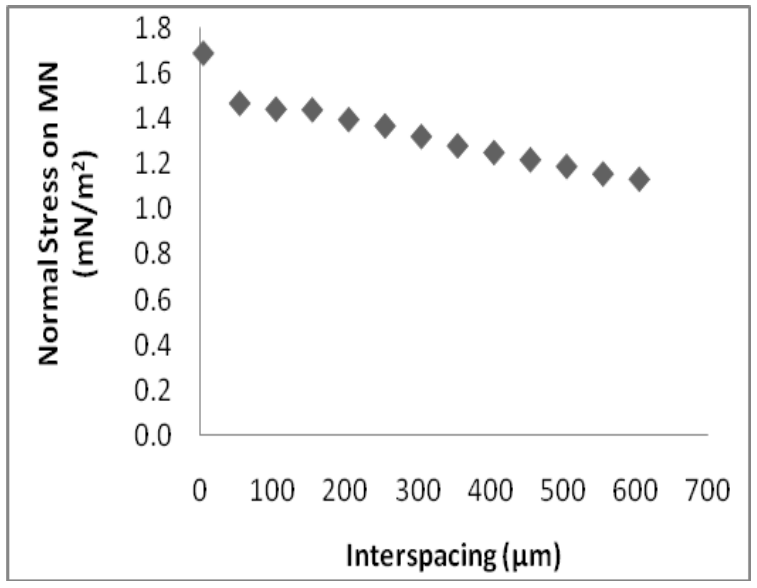

(a)

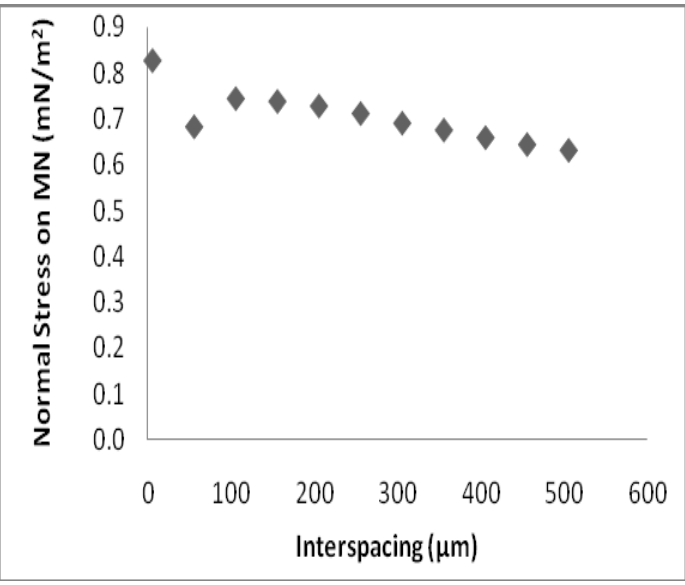

(b)

Figure 4. Normal stress on (a) microneedle geometry used within the in vitro insertion force determination experiments. (b) Theoretical MN design of $400 \mu \mathrm{m}$ height and a smaller wall angle than the polymeric conical shape MNs employed in the experimental section. 


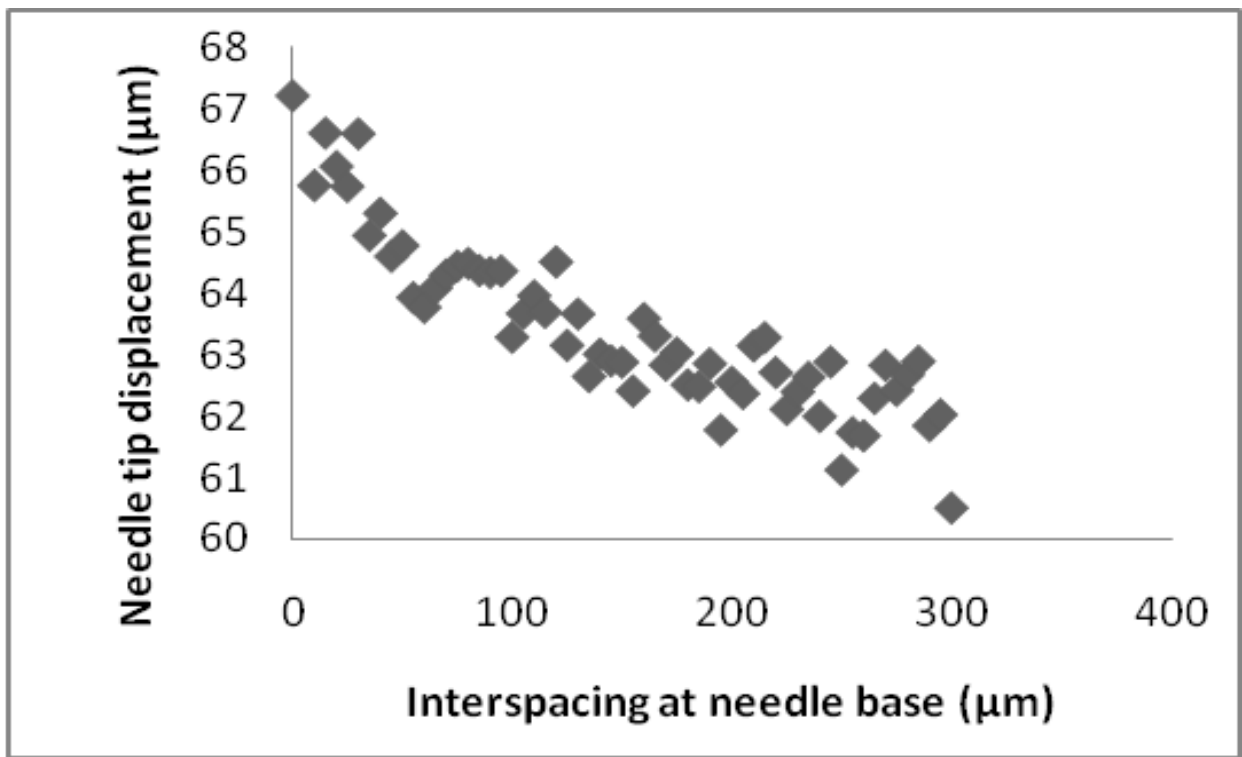

Figure 5. The vertical displacement decreases as the spacing is increased indicating that spacing has a significant impact on the manner in which skin deforms. 


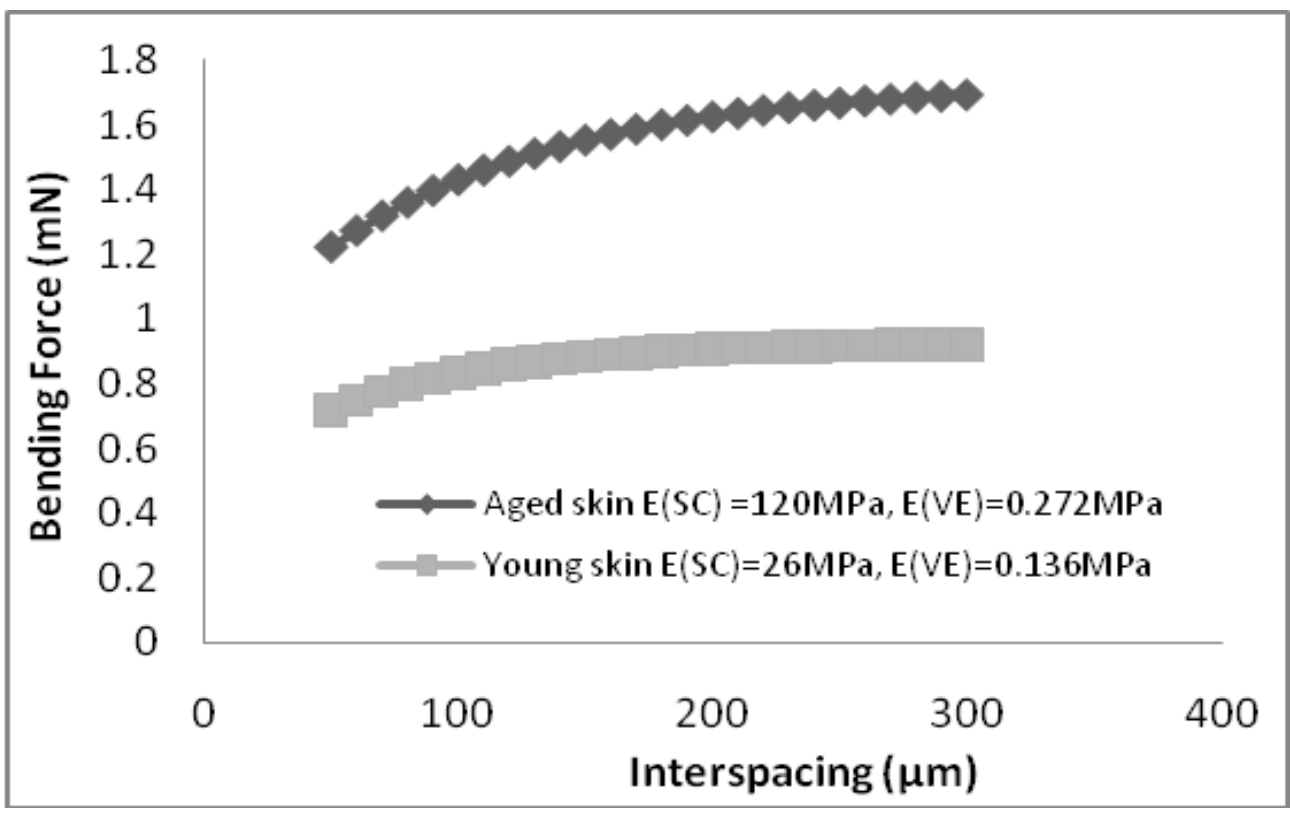

Figure 6. The force required to cause skin bending as a function of MN interspacing. 


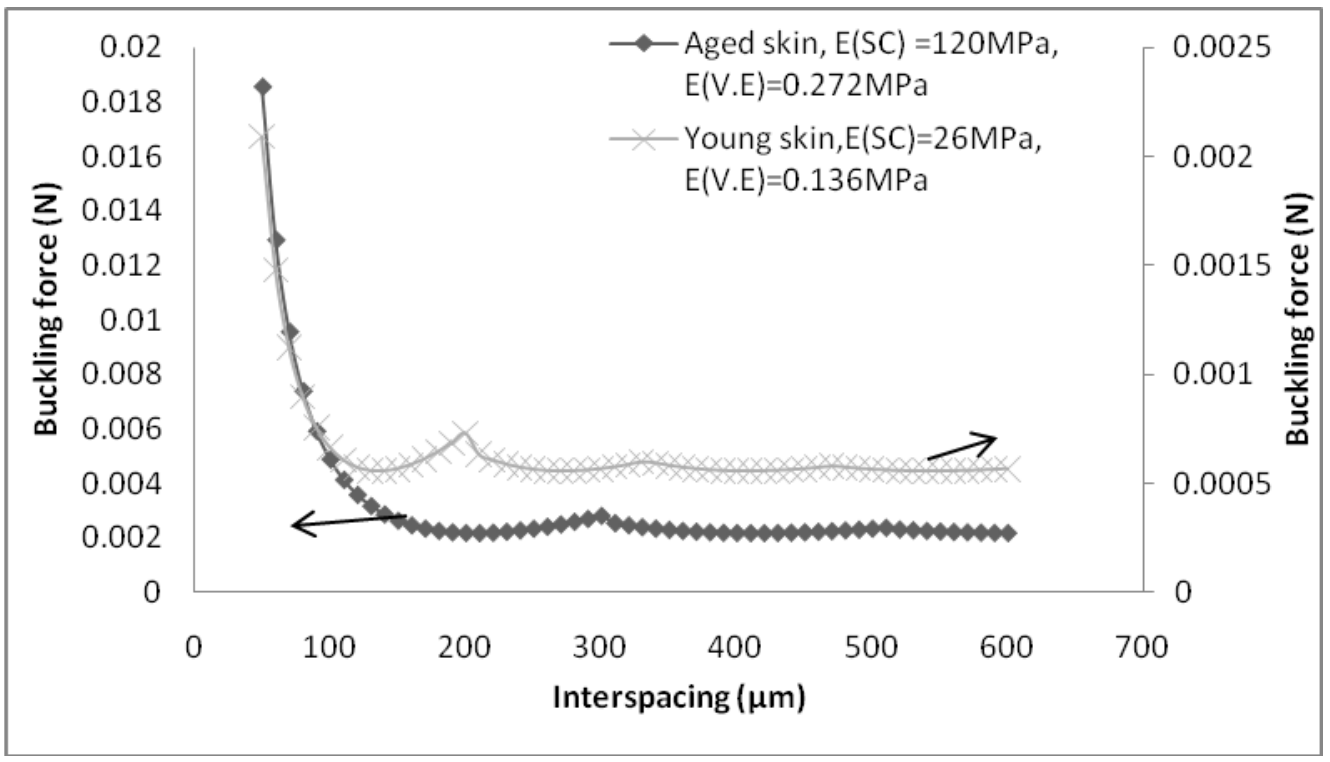

Figure 7. Effect of MN interspacing on buckling force for aged and young animal skins 


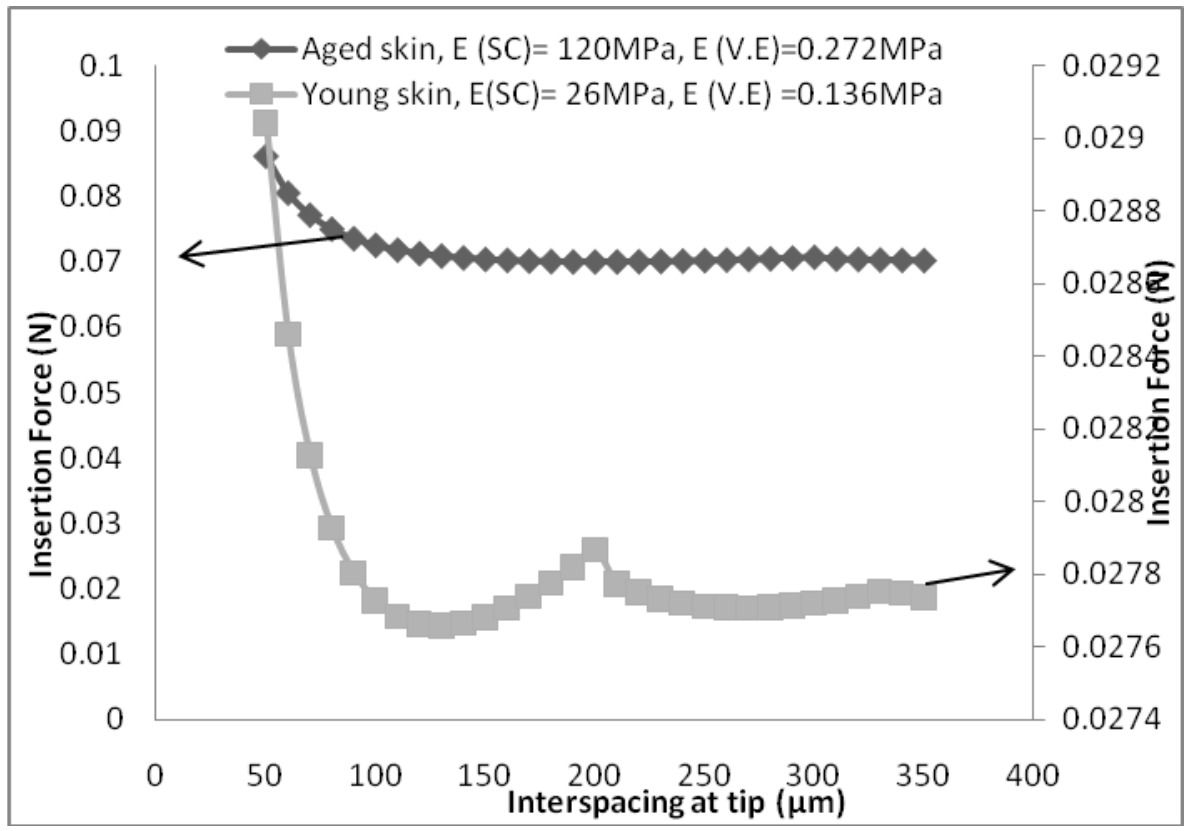

Figure 8. Effect of $\mathrm{MN}$ interspacing on the force required $\mathrm{MN}$ insertion into skin. 


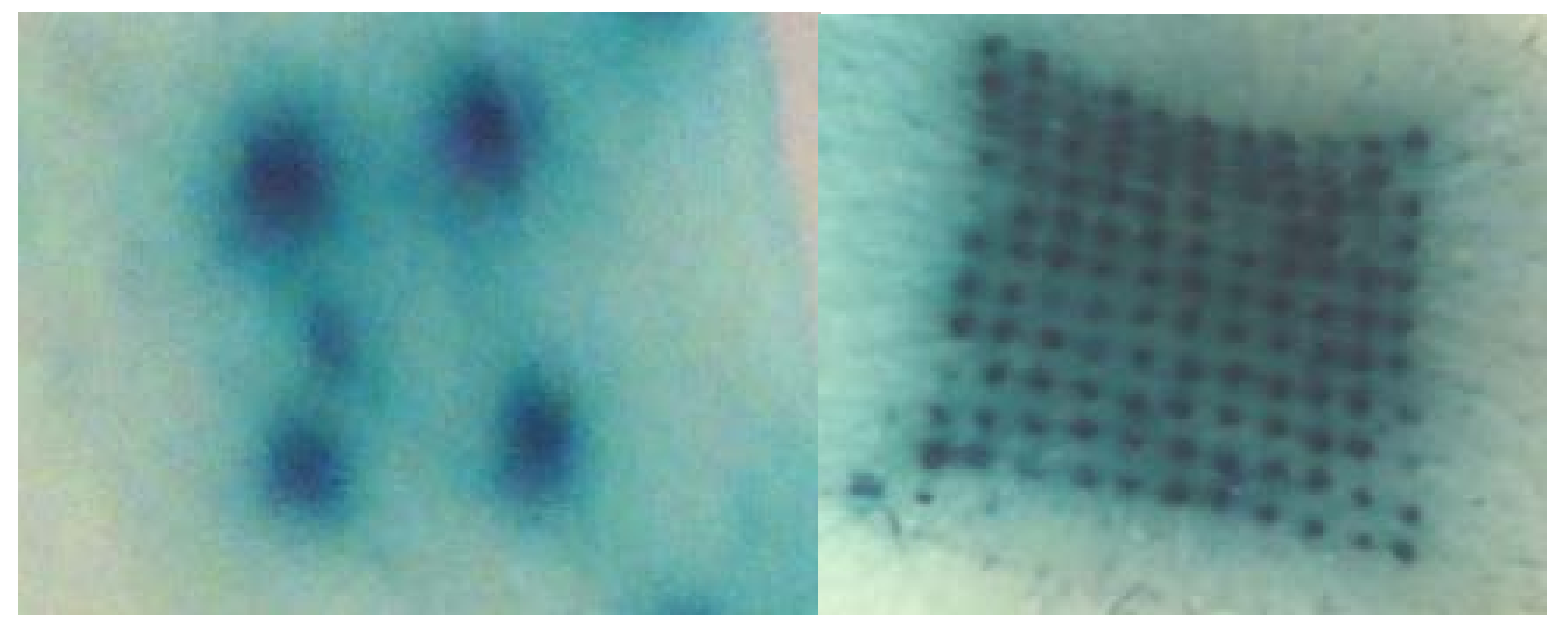

Figure 9. Representative digital images highlighting the penetration of a MN array with 4 MNs / array on the left, and 121 MNs / array on the right. 


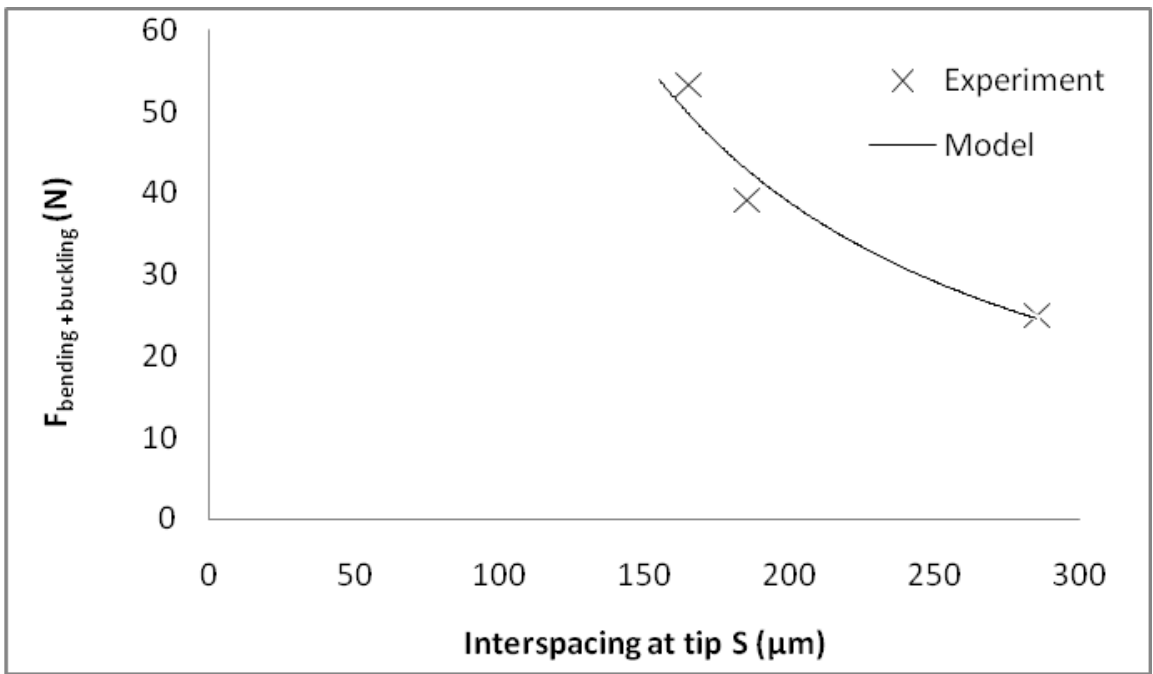

Figure 10. Buckling and bending force ( $F_{\text {buckling+bending }}$ ) at different interspacing of microneedles (S) 